\title{
Using mixed frequency data to improve macroeconomic forecasts of inventory investment
}

\author{
Michael R. Donihue \\ Colby College, Waterville, ME 04901, USA \\ E. Philip Howrey \\ University of Michigan, Ann Arbor, MI 48109, USA
}

\begin{abstract}
This paper briefly reviews and extends the evidence on the importance of inventory investment in business cycles. A method for combining high-frequency observations with forecasts of a conventional quarterly econometric model is then proposed. The method is applied to the Michigan Quarterly Econometric Model of the U.S. Economy to see if improved forecasts of inventory investment can be obtained. The use of a small set of monthly indicators is found to yield improved forecasts of real GNP but are of little help in forecasting inventory investment. A more comprehensive set of monthly indicators including inventory and sales may be needed to obtain improved estimates of quarterly inventory investment.
\end{abstract}

\section{Introduction}

During the past four decades, economists have documented and studied the important role inventory investment plays in explaining business cycles in the US economy. Blinder [1,2], Blinder and Holtz-Eakin [3], Reagan and Sheehan [4] and Ramey [5] have provided empirical evidence supporting the notion that inventories do matter in the determination of business cycles. This evidence suggests that accurate and timely forecasts of inventory investment might help in predicting the length and severity of business cycles. In this paper we update some of the stylized facts concerning the role of inventory investment and propose a method for the prediction of inventory investment that incorporates high frequency data in a conventional macroeconometric model of the US economy.

\section{The importance of inventories in business cycles}

A survey of recessions during the postwar years in the United States shows the importance of in- ventory investment in times of economic decline. Since 1947 , inventory investment has averaged only $0.6 \%$ of real GNP. However the decline in inventory investment has averaged $93 \%$ of the decline in real GNP during the eight recessions which have occurred over this period. In the most recent recession, $90 \%$ of the decline in real GNP was accounted for by a drop in real inventory investment. It is interesting to note that during this recession consumption and government spending actually increased, while real fixed investment fell by $\$ 57$ billion and real net exports declined by $\$ 30$ billion.

Another way to examine the importance of inventory investment in accounting for changes in output is to perform a spectral decomposition of the variance of changes in output. If we define the cyclical components of real GNP, real final sales and real inventory investment as the period-to-period changes and assume that each is covariance stationary (with absolutely summable covariance functions) then a frequency domain decomposition of the variance of real GNP is given by 


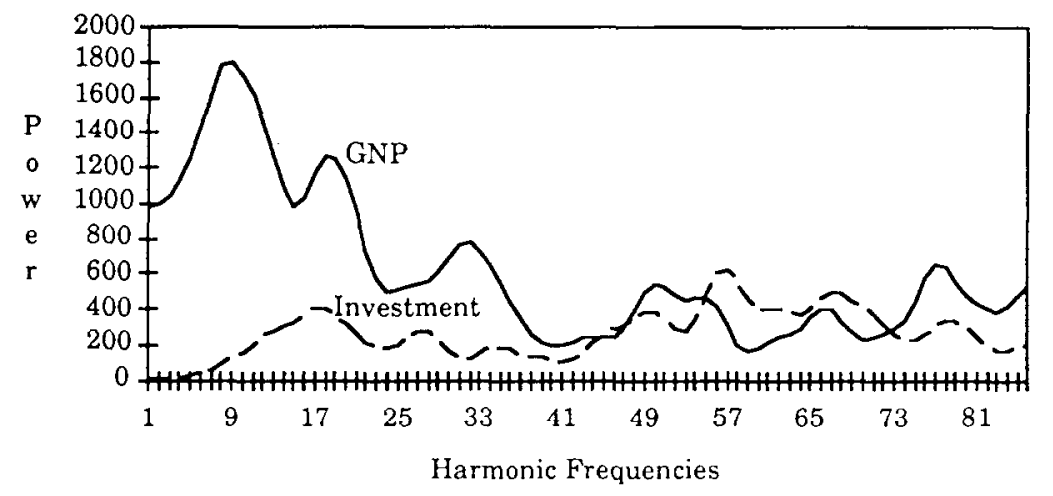

Fig. 1. Spectrum estimates.

$f_{y y}(\omega)=f_{x x}(\omega)+f_{i i}(\omega)+f_{x i}(\omega)+f_{i x}(\omega)$

where $f_{v v}(\omega)$ denotes the spectrum of the cyclical component of GNP, $y_{t}$, and $f_{x i}(\omega)$ denotes the cross-spectrum of the cyclical components of real final sales and inventory investment, respectively, $x_{t}$, and $i_{r}$. Figure 1 displays estimates of the spectra of $y_{t}$ and $i_{t}{ }^{1}$. The most interesting feature of these spectral estimates is that inventory investment has much less power at the low-frequency end of the spectrum than does GNP. On the basis of these estimates, one might question the importance of inventory investment in accounting for variations in GNP, especially at a business-cycle frequency in the range of four to six years ${ }^{2}$.

We get a very different result if we instead focus on the conditional variance of GNP given investment in inventories. Algebraically, the conditional variance of $y$ given $i$ at frequency $\omega$ can be expressed as

$f_{u u}(\omega)=f_{y v}(\omega)-\frac{\left|f_{y i}(\omega)\right|^{2}}{f_{i i}(\omega)}$

Figure 2 shows the spectral estimates corresponding to a decomposition of the conditional

\footnotetext{
${ }^{1}$ The Parzen window with 12 equivalent degrees of freedom was used to obtain these estimates of the spectrum. The ordinates are plotted at the harmonic frequencies $(2 \pi j / T)$ so that a four-year business cycle corresponds to $j=11$ on the horizontal axis.

${ }^{2}$ In Fig. 1 the spectrum of the cyclical component of real GNP peaks at a harmonic frequency of 9 . Given 171 observations this corresponds to a business cycle frequency of 19 quarters, or approximately 5 years.
}

variance of $y_{t}$ given $i_{t}$. Here it is clear that conditioning on inventory investment reduces the variance of GNP very dramatically at the businesscycle frequencies. It seems clear from these estimates that the importance of inventory investment in shaping fluctuations in real GNP is not merely a short-run, high frequency phenomenon. These conditional variance calculations seem to be particularly supportive of the notion that inventory movements are an especially important factor in business-cycle variations.

Thus it seems clear that inventory investment does matter in the determination of fluctuations of real GNP. In fact inventories play a major role in the decomposition of variations in the periodto-period growth of real output. The spectral analysis presented in this section suggests that if we knew, or could predict, the level of inventory investment we might come up with a more accurate prediction of the level of real GNP. This is the issue which we will explore in greater detail in the next sections of this paper.

\section{Combining forecasts of differing periodicities}

The idea of combining two or more forecasts in order to obtain an improved, or in some cases statistically optimal forecast is not a new one. Indeed the univariate approach to combining forecasts has been well documented and studied for a number of years (see Granger and Newbold [6]). Less work has been done however on the combination of multivariate forecasts of differing periodicities. In this section we introduce a procedure for combining multivariate forecasts 


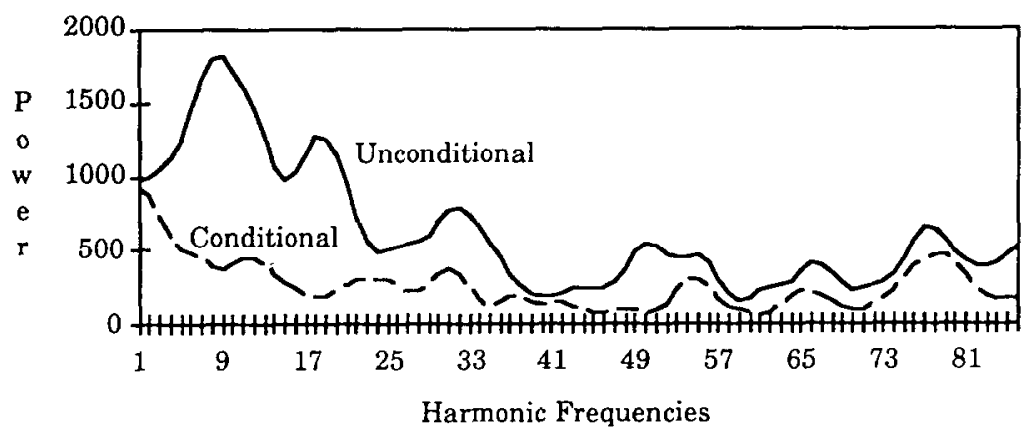

Fig. 2. Decomposition of the conditional and unconditional variance of GNP.

which incorporates high frequency (monthly) data into a conventional (quarterly) macroeconometric model of the US economy.

Most of the macroeconomic forecasting models in the United States are based on quarterly data. Some of the variables included in these models represent aggregates of information reported on a more frequent basis. For example, interest rates are generally considered to be important indicators of economic activity and are commonly forecast by quarterly structural econometric models. Yet most interest rates are reported historically on a monthly, or even weekly basis. In some cases forecasts must be generated prior to the completion of the current quarter. In other cases forecasts may be updated each month as new information becomes available. In both situations, high frequency information plays a role in adjusting the quarterly forecast in the current quarter and beyond. Usually, such high frequency data are incorporated into quarterly macroeconomic forecasts in a subjective, ad hoc fashion. Howrey, Hymans and Donihue [7] and Donihue [8] provide the analytical foundations for a more formal method of combining forecasts of differing frequencies and established the potential for significantly improving the accuracy of quarterly forecasts using a conditional expectations approach.

The conditional expectations approach begins with forecasts from a quarterly structural macroeconometric model which can be represented as a system of $G$ nonlinear equations as

$F\left(Y_{T}, Y_{T-1}, X_{T} ; \Theta\right)=U_{T}$

where, $Y_{T}$ is a $G \times 1$ vector of variables whose values are to be determined in quarter $T, X_{T}$ is a
$K \times 1$ vector of exogenous variables in quarter $T$, $\Theta$ is the corresponding vector of parameters, and $U_{T}$ is a $G \times 1$ vector of disturbances in quarter $T$. $Y_{T_{-1}}$ is included to reflect the fact that this is a dynamic model which may include higher-order lags on the endogenous variables as well as lagged exogenous variables.

Forecasts of monthly indicators of economic activity are assumed to be generated by a welldefined statistical model consisting of $g$ equations which we shall write as

$f\left(y_{t}, y_{t-1}, x_{t} ; \theta\right)=u_{t}$

where $y_{t}$ is a vector of monthly observations for the $g$ endogenous variables in month $t^{3}, x_{t}$ is a $k$ dimensional vector of monthly observations on the exogenous variables, $\theta$ is the corresponding parameter vector, and $u_{t}$ is a $g$-dimensional vector of disturbances in month $t$. The monthly model need not be linear and it does not necessarily have to contain any exogenous variables.

The variables in the quarterly and monthly models will be related in two ways. First, there will be an aggregation condition, i.e., a subset of $m$ variables in the quarterly model will simply be aggregates of the monthly variables. Second, errors made in forecasting the variables in the monthly model will, in general, be correlated with the forecast errors of the quarterly model. At the beginning of the first forecast quarter, $N+1$, a one-quarter-ahead forecast based solely on the quarterly model is obtained by solving

\footnotetext{
${ }^{3}$ The time indices, $T$ for the quarterly and $t$ for the monthly observations, can be thought of as being related by the expression $T=\langle 1 / 3\rangle$ where $\langle 1 / 3\rangle$ denotes the smallest integer greater than or equal to $1 / 3$.
} 
$F\left(\hat{Y}_{N+1}, Y_{N}, X_{N+1} ; \hat{\Theta}\right)=0$

for $\hat{Y}_{N+1}$. Since no monthly data for the current quarter are available, the endogenous variables in the monthly model must be forecast by solving recursively, for each of the three months of the quarter, the following set of equations:

$f\left(\hat{y}_{n+1}, y_{n}, x_{n+1} ; \hat{\theta}\right)=0$

$f\left(\hat{y}_{n+2}, \hat{y}_{n+1}, x_{n+2} ; \hat{\theta}\right)=0$

$f\left(\hat{y}_{n+3}, \hat{y}_{n+2}, x_{n+3} ; \hat{\theta}\right)=0$

The forecasts from eqns. (5-8) are collected into the $G+3 g$-dimensional vector of predicted values

$\hat{\mathscr{Y}}_{N+1}^{\prime}=\left(\hat{Y}_{N+1}^{\prime} \hat{y}_{n+3}^{\prime} \hat{\mathcal{y}}_{n+2}^{\prime} \hat{y}_{n+1}^{\prime}\right)$

Thus

$\mathscr{Y}_{N+1}=\hat{\mathscr{G}}_{N+1}+\mathscr{U}_{N+1}$

The linkages between the quarterly and monthly models described above provide information about the vector of reduced form disturbances, $\mathscr{U}_{N+1}$, which can be used to generate an improved forecast of $\mathscr{Y}_{N+1}$. The aggregation condition can be written as

$Q \mathscr{Y}_{N+1}=0$

where

$Q=(\mathscr{T}-s / 3-s / 3-s / 3)$

and $\mathscr{T}$ and $s$ are matrices, with dimensions $m \times G$ and $m \times g$ respectively, which select all variables in common to the quarterly and monthly models. The fact that the elements in $\mathscr{Y}_{N+1}$ are related by this condition means that $Q \mathscr{U}_{N+1}=-Q \hat{\mathscr{Y}}_{N+1}$. Now let $\mathscr{X}_{N+1}=Q \mathscr{U}_{N+1}$. Assuming that $\mathscr{U}_{N+1} \sim$ $\mathcal{A}(0, \Phi)$, then

$\left(\begin{array}{l}\mathscr{U}_{N+1} \\ x_{N+1}\end{array}\right) \sim \mathscr{N}(0, \Pi)$

where

$\Pi=\left(\begin{array}{cc}\Phi & \Phi Q^{\prime} \\ Q \Phi & Q \Phi Q^{\prime}\end{array}\right)$

In general, $\hat{\mathscr{Y}}_{N+1}$ will not necessarily satisfy the aggregation condition of eqn. (11). Therefore the first step in combining monthly and quarterly forecasts is to adjust them so that the common variables satisfy the aggregation condition. Using standard formulas for the multivariate normal distribution, Donihue [8] showed that an improved forecast of $\mathscr{Y}_{N+1}$ (relative to $\hat{\mathscr{Y}}_{N+1}$ ) based on $\hat{\mathscr{Y}}_{N+1}$ and $\mathscr{X}_{N+1}$ will be

$$
\begin{aligned}
\overline{\mathscr{Y}}_{N+1} & =\hat{\mathscr{Y}}_{N+1}+\mathscr{E}\left[\mathscr{U}_{N+1} \mid \mathscr{X}_{N+1}=-Q \hat{\mathscr{Y}}_{N+1}\right] \\
& =\hat{\mathscr{Y}}_{N+1}-\Phi Q^{\prime}\left(Q \Phi Q^{\prime}\right)^{-1} Q^{\hat{\mathscr{Y}}_{N+1}}
\end{aligned}
$$

with a corresponding conditional covariance matrix of

$\Psi=\Phi-\Phi Q^{\prime}\left(Q \Phi Q^{\prime}\right)^{-1} Q \Phi$

Thus $\overline{\mathscr{Y}}_{N+1}$ is the " 0 months known", onequarter-ahead, combined forecast of $\mathscr{Y}_{N+1}$. Note that $\mathscr{Y}_{N+1}$ satisfies the aggregation condition of eqn. (11). Furthermore, note that $\Psi-\Phi$ is a negative semi-definite matrix, and that the corresponding diagonal elements of $\Psi$ and $\Phi$ reflect the anticipated improvement in forecast accuracy resulting from this procedure.

As the current quarter unfolds, and more monthly data become available, the initial combined forecast can be updated by conditioning successively on the observed monthly values. These values provide information to the quarterly forecast in two ways. First, the aggregation condition continues to hold for the common variables. This alone leads to a reduction in the prediction error variance of the quarterly aggregates for the common variables. Second, the monthly model can be used to calculate the vector of first month disturbances when data for the first month are known and again for the second month once those values are realized. As noted earlier, these disturbances will in general be correlated with the quarterly disturbances. These correlations are captured in the covariance matrix of the structural disturbances, and reflected in the covariance matrix of reduced form disturbances $\Phi$. Both linkages can be used to compute new forecasts of $\mathscr{Y}_{N+1}$ based on $\hat{y}_{N+1}$, the information in $\mathscr{X}_{N+1}$ implied by the aggregation condition, and the available monthly data. 


\section{Application and results}

The quarterly macroeconometric forecasting model used in this study was the Michigan Quarterly Econometric Model of the US Economy (MQEM). MQEM is maintained by the Research Seminar in Quantitative Economics (RSQE) at the University of Michigan and is used to produce quarterly forecasts on a regular basis throughout the year. On twelve different occasions during 1986, 1987 and 1988 forecasts were generated using the version of MQEM, and the historical data, as it existed at that time, relying on subjectively determined forecast paths for the exogenous variables. Four forecasts, dated in February, May, August and November in each year were chosen for this study. Each represents an "early quarter forecast" in the sense that the initial conditions on which the forecasts are based reflect the preliminary estimates of the National Income and Product Accounts for the last "known" quarter. As a result, there is less information on which to base a forecast for the current quarter than during other times of the year and hence the greatest potential gain for incorporating higher frequency information into the MQEM forecasts in a systematic fashion. The monthly model chosen for this analysis included four variables from the following sectors of the US economy: output, as reflected by the rate of growth of the Manufacturing Index of Industrial Production; inflation, as measured by the rate of growth in the Consumer Price Index; money and investment, as reflected in the 3 Month Treasury Bill rate; and the Civilian Unemployment rate. A second-order, vector autoregressive (VAR) model was chosen as our monthly forecasting model.

The procedure for combining forecasts from MQEM and the monthly VAR model follows that outlined in the preceding section. Table 1 and the two panels of Fig. 3 illustrate some of the theoretical improvements we can expect from using this procedure to generate ex ante forecasts in real time. Table 1 presents average forecast standard errors for one-quarter-ahead forecasts for a subset of variables in MQEM. The data in this table represent averages of the diagonal elements of the covariance matrices of forecast errors generated from using MQEM alone and from our com- bined forecasting technique. As such they represent anticipated or theoretical improvements in forecast accuracy which result from combining forecasts from the two models.

Note that for each variable in Table 1 the estimated standard errors decrease as the models are combined, and are reduced further as more information becomes available during the current quarter. For example, the estimated standard error for a one-quarter-ahead forecast of real GNP using MQEM alone is $\$ 30.87$ billion. By combining this forecast with forecasts generated using the monthly model (before any current-quarter information becomes available) the standard error of the forecast of real GNP is reduced to $\$ 21.477$ billion. With one month in the current quarter known, the estimated standard error is $\$ 17.705$ billion and with two months known the standard error falls to just over $\$ 16$ billion.

For nonlinear models these standard errors will be time dependent. Figure 3 presents estimated standard errors for two of the variables in MQEM for the twelve forecasts generated during 1986, 1987 and 1988. Plotted in these two panels are: the square roots of the corresponding diagonal elements of the covariance matrix of forecast errors for MQEM alone, which appear as the curve labeled MQEM; and the same elements of the estimated covariance matrices of combined forecast errors for zero, one and two months of the current quarter known. These curves are labeled. 0 Months, 1 Month, and 2 Months respectively.

Several interesting results emerge from the graphs in Fig. 3. Consider the panel for real GNP. Combining forecasts causes the one-quarterahead forecast standard errors to decrease quite dramatically relative to the MQEM forecasts alone. The gains by including additional months of information appear to be decreasing over time for real GNP as the 0,1 and 2 months curves trend upward at the end of this sample period. Perhaps the most interesting results occur when the MQEM and combined forecast curves diverge over time. Inventory Investment presents such a phenomenon in which the combined forecast error variance is expected to decline over this forecast period.

Actual improvements in forecast accuracy are shown in Table 2 which contains root mean 
TABLE 1

Average forecast standard errors

\begin{tabular}{|c|c|c|c|c|c|}
\hline \multirow[t]{2}{*}{ Endogenous variable } & \multirow[t]{2}{*}{ Units } & \multicolumn{4}{|c|}{ One-quarter-ahead forecasts } \\
\hline & & MQEM & $\begin{array}{l}0 \text { months } \\
\text { known }\end{array}$ & $\begin{array}{l}1 \text { month } \\
\text { known }\end{array}$ & $\begin{array}{l}2 \text { months } \\
\text { known }\end{array}$ \\
\hline GNP & Bil '82 \$'s & 30.870 & 21.477 & 17.705 & 16.206 \\
\hline Ratc of growth & $\%, A R$ & 3.425 & 2.319 & 1.896 & 1.719 \\
\hline Business fixed investment & Bil '82 \$'s & 11.321 & 9.994 & 9.645 & 8.089 \\
\hline Inventory investment & Bil '82\$'s & 23.546 & 20.940 & 18.117 & 17.338 \\
\hline Civilian unemployment rate & $\%$ & 0.250 & 0.178 & 0.136 & 0.054 \\
\hline Pvt nonfarm GNP deflator & $\%, \mathrm{AR}$ & 2.090 & 1.143 & 1.072 & 0.897 \\
\hline 3 month treasury bill rate & $\%$ & 0.547 & 0.391 & 0.301 & 0.133 \\
\hline Corporate Aaa rate & $\%$ & 0.610 & 0.449 & 0.409 & 0.364 \\
\hline Value of US dollar & $3 / 73=100$ & 1.412 & 1.225 & 1.136 & 1.013 \\
\hline Federal budget deficit & Bil \$'s & 11.213 & 8.645 & 7.429 & 6.664 \\
\hline
\end{tabular}

For forecasts made in February, May, August and November of 1986, 1987 and 1988.
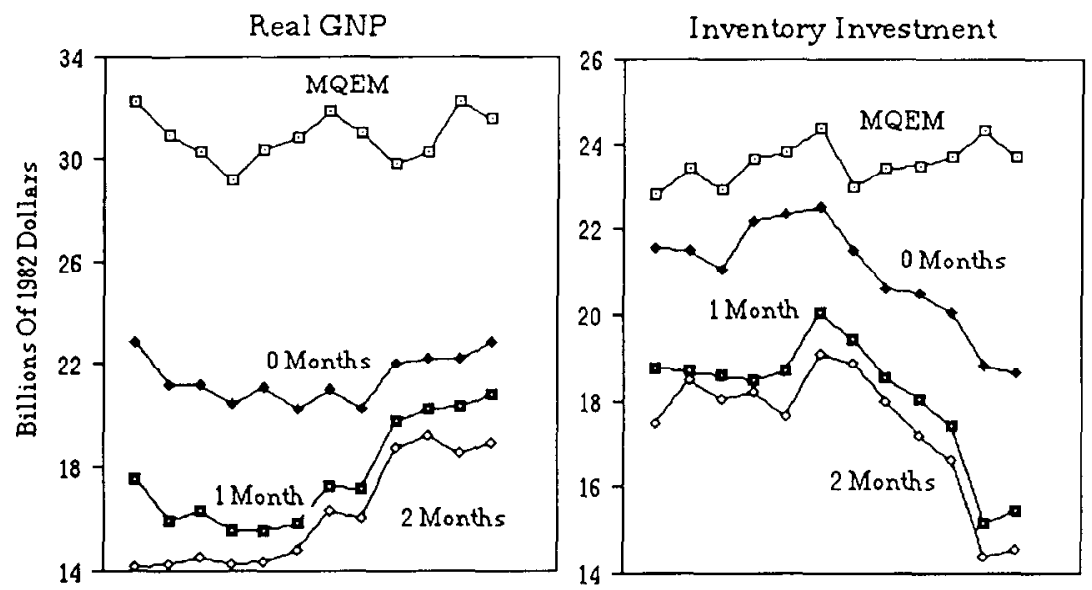

Fig. 3. Estimated standard errors for one-quarter-ahead forecasts.

squared errors (rmse) for a subset of the quarterly variables in MQEM calculated over the twelve ex ante forecasts described earlier. The first column of Table 2, designated as RSQE, refers to the actual one-quarter-ahead published forecasts obtained using the quarterly model in conjunction with subjectively determined adjustment constants. The RSQE forecasts are published early in the second month of the quarter and are based on the limited amount of currentquarter information which has been released by that time, e.g., employment and interest rates. The second set of forecasts, identified as MQEM, was generated using the quarterly model by itself. The MQEM forecasts are based entirely on information for the preceding quarter and reflect the collective judgement of the forecasters at RSQE only through the specification of the values of the exogenous variables in the model. The third forecasting method shown in Table 2 is the combined procedure described earlier. In terms of the information available at the time the forecasts were made, the MQEM and the combined forecast with no current-quarter monthly data ( 0 months known ) are comparable while the RSQE forecast is comparable to the 1 month known combined forecast. The results in this table show that combining forecasts from the two models yields a significant improvement in the rmse for most variables with further improvements oc- 
TABLE 2

A comparison of root mean squared errors

\begin{tabular}{|c|c|c|c|c|c|}
\hline \multirow[t]{2}{*}{ Endogenous variable } & \multicolumn{5}{|c|}{ Onc-quarter-ahcad forccasts } \\
\hline & RSQE & MQEM & $\begin{array}{l}0 \text { months } \\
\text { known }\end{array}$ & $\begin{array}{l}1 \text { month } \\
\text { known }\end{array}$ & $\begin{array}{l}2 \text { months } \\
\text { known }\end{array}$ \\
\hline$G N P^{1.5}$ & 26.58 & 40.31 & 24.84 & 25.83 & 36.57 \\
\hline Rate of growih ${ }^{3}$ & 2.83 & 4.53 & 2.71 & 2.77 & 3.94 \\
\hline \multicolumn{6}{|l|}{ Personal consumption } \\
\hline Nondurables ${ }^{1,5}$ & 9.26 & 17.98 & 7.40 & 7.77 & 7.70 \\
\hline Durables ${ }^{1.5}$ & 13.06 & 10.78 & 10.29 & 11.52 & 11.55 \\
\hline Business fixed investment ${ }^{1.5}$ & 11.66 & 9.44 & 9.78 & 9.81 & 11.63 \\
\hline Inventory investment 1.5 & 24.25 & 26.76 & 26.43 & 21.26 & 24.64 \\
\hline Net exports 1.5 & 14.349 & 13.74 & 23.62 & 22.58 & 20.39 \\
\hline Civilian unemployment rate ${ }^{2}$ & 0.18 & 0.15 & 0.15 & 0.13 & 0.08 \\
\hline Pvt nonfarm GNP deflator ${ }^{3}$ & 2.08 & 2.93 & 2.54 & 2.49 & 2.16 \\
\hline 3 month treasury bill rate ${ }^{2}$ & 0.18 & 1.06 & 0.76 & 0.54 & 0.24 \\
\hline Corporate Aaa rate $\mathrm{e}^{2}$ & 0.19 & 0.72 & 0.93 & 0.87 & 0.79 \\
\hline Value of US dollar ${ }^{4}$ & 1.30 & 3.23 & 3.90 & 3.72 & 3.63 \\
\hline Federal budget deficit ${ }^{5}$ & 29.06 & 31.71 & 29.04 & 30.92 & 31.38 \\
\hline
\end{tabular}

'Billions of 1982 dollars.

${ }^{2}$ Percent.

${ }^{3}$ Percent annual rate of growth.

${ }^{4}$ Index: March $1973=100$.

${ }^{5}$ Calculated from differences between predicted and actual changes.

For forecasts made in February, May, August and November of 1986, 1987 and 1988 using July 1990 actuals.

curring as more information becomes available during the current quarter.

The results for real GNP are shown in the first line of Table 2. RSQE's forecasts had an rmse of $\$ 26.58$ billion (1982 dollars). The combined forecast with no months of the current quarter known, with an rmse of $\$ 24.84$ billion, was the most accurate of all the forecasts for this variable. Note that this represents a significant improvement over forecasts generated using MQEM alone (which had an rmse of $\$ 40.31$ billion). With one month of the first forecast quarter known the rmse for the combined forecasts increased to $\$ 25.84$ billion - still less than the RSQE forecasts. Then with two months of the current quarter known the rmse somewhat surprisingly increased again to $\$ 36.57$ billion. Remember that, as a general rule, combining forecasts from the two models is expected to yield improvements in forecast accuracy with further improvements occurring as more information becomes available during the current quarter. While for some of the variables in Table 2 the results are inconsistent with what we anticipated, many of the results do follow the pattern of the theoretical improvements presented in Table 1 . In the case of real inventory investment for example, the pattern of average forecast standard errors in Table 1 is essentially consistent with the actual results observed in Table 2 .

Figure 4 illustrates precisely how the procedure for combining forecasts works for onequarter-ahead forecasts of real inventory investment. For the twelve forecasts made in 1986 , 1987 and 1988, each figure plots a one standard error confidence interval about the following point forecasts: (i) MQEM by itself; (ii) the 0 months known combined forecast; (iii) the 1 month known combined forecast; and (iv) the combined forecast with 2 months known. The large dot (•) at the midpoint of the forecast interval represents the corresponding point forecast. Also plotted (without a confidence interval) is an asterisk which represents the RSQE ex ante forecast. The actual value as it is presently 


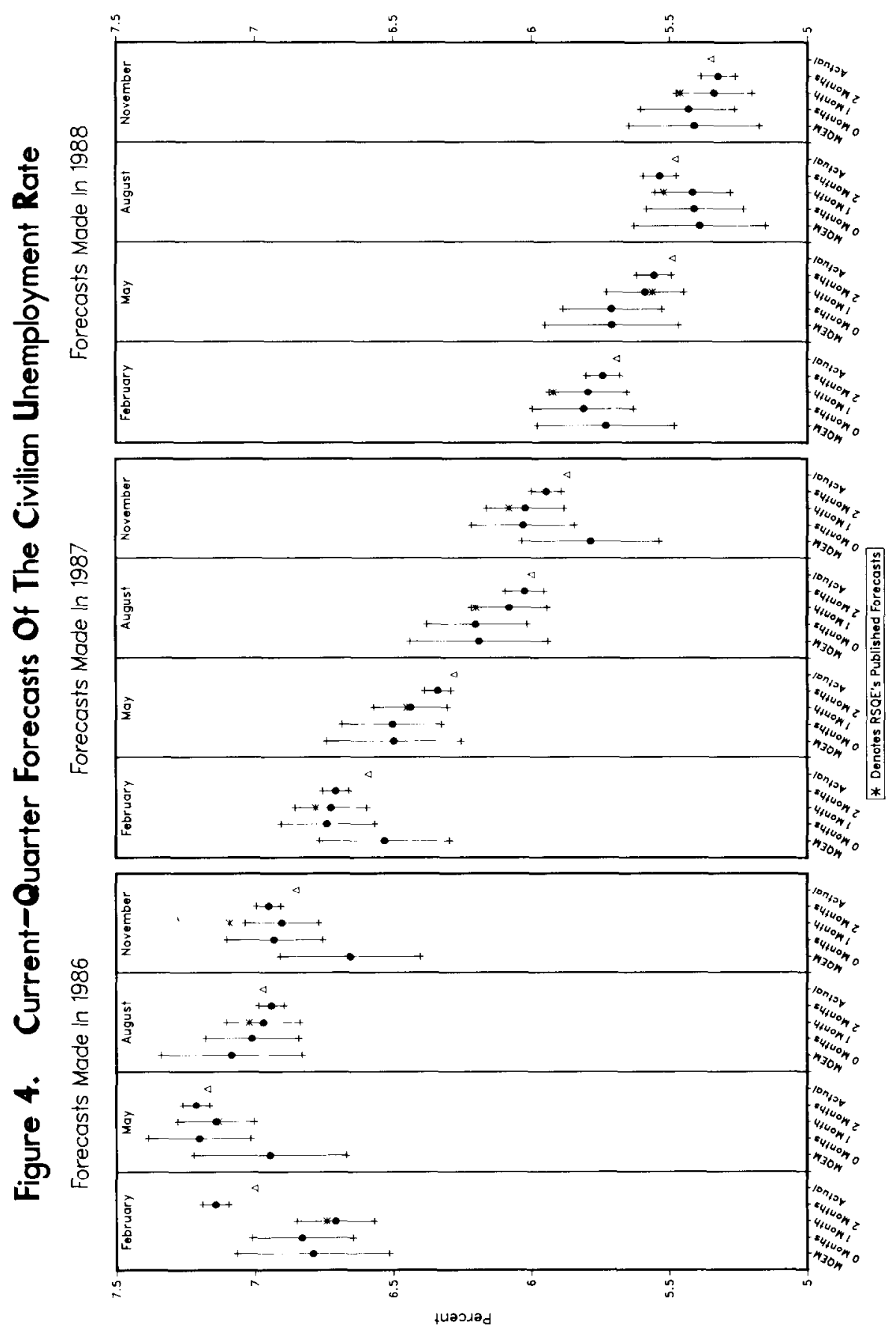

Fig. 4. Current-quarter forecasts of real inventory investment. 
known ${ }^{4}$ is shown as the last point in the sequence and plotted as a triangle $(\Delta)$.

Consider the sequence of forecasts for the first quarter of 1987. The forecast using MQEM alone was for real inventory investment to be $\$ 32$ billion (1982 dollars), plus or minus a one standard error confidence interval of $\$ 23.8$ billion. The 0 months known combined forecast and corresponding confidence interval was $\$ 23$ billion \pm $\$ 22.4$ billion. After the first month's data for the first quarter of 1987 became available, the combined forecast was updated to be $\$ 21.7$ billion \pm $\$ 18.7$ billion. At about the same point in time, RSQE was predicting a level of inventory investment of less than $\$ 1$ billion for the first quarter of 1987. After the data for February 1987 were known, the combined forecast was again updated to $\$ 23$ billion $\pm \$ 17.6$ billion. Inventory investment actually turned out to be $\$ 17.3$ billion - well within each of the confidence intervals for the three combined forecasts made during that period.

Very few of the actual levels of inventory investment shown in Fig. 4 lie within a one standard error confidence interval of any of the combined forecasts. However this does not necessarily mean that the procedure is flawed. In fact the procedure works quite well at predicting real GNP growth over this period. Recall that the principle indicator of aggregate economic activity in the monthly model is the Manufacturing Index of Industrial Production, which is not a very accurate indicator of inventory investment. Monthly information on inventories and sales may be necessary to obtain improved forecasts of inventory investment.

\section{Conclusions}

This paper has only briefly reviewed the vast amount of information which is contained in the twelve forecasts for which the combined fore-

\footnotetext{
${ }^{4}$ Actual values plotted in Fig. 4 are as reported by the July 1990 NIPA release.
}

casting procedure was implemented. One thing is clear from these results however, and that is that the procedure works well for some variables. Not only is it feasible to combine forecasts of differing periodicities in the context of a real-time macroeconometric forecasting activity, but also doing so leads to better forecasts. Better in the sense that the forecasts are more accurate than those generated by the macroeconometric model alone, and better because it provides a formal method for producing accurate forecasts which does not rely on the judgement or expertise of an individual forecaster. Our current research effort involved redefining the monthly model to incorporate high frequency information on inventory investment. This should lead to more accurate forecasts of real inventory investment on a quarterly basis and may improve our forecasts of real GNP growth as well.

\section{References}

1 Blinder, A.S., 1981. Retail inventory behavior and business fluctuations. Brookings Papers Econ. Activity, 2: $443-$ 520 .

2 Blinder, A.S., 1981. Inventories and the structure of macro models. AEA Papers Proc., 71: 11-16.

3 Blinder, A.S. and Holtz-Eakin, D., 1986. Inventory fluctuations in the United States since 1929. In: R.J. Gordon, (ed.), The American Business Cycle, National Bureau of Economic Research, The University of Chicago Press, pp. 183-236.

4 Reagan, P. and Sheehan, D.P., 1985. The stylized facts about the behavior of manufacturers' inventories and backorders over the business cycle: 1959-1980. J. Monetary Econ., 15: 217-246.

5 Ramey, V.A., 1989. Inventories as factors of production and economic fluctuations. Amer. Econ. Rev., 79: 338354.

6 Granger, C.W.J. and Newbold, P., 1986. Forecasting Economic Time Series, 2nd edition. Academic Press, Orlando, FL.

7 Howrey, E.P., Hymans, S.H. and Donihue, M.R., 1991. Merging monthly and quarterly forecasts: Experience with MQEM. J. Forecast., 10: 255-268.

8 Donihue, M.R., 1989. On the use of mixed frequency data to improve macroeconometric forecasts. Unpublished doct. dissertation, University of Michigan. 